\title{
DINÂMICA E CARACTERIZAÇÃO FLUVIAL DA BACIA DO RIACHO GRANDE, SERRA TALHADA - PE: ABORDAGEM DA CONECTIVIDADE DA PAISAGEM
}

\author{
DYNAMICS AND FLUVIAL CHARACTERISTIS OF THE RIACHO GRANDE BASIN, SERRA TALHADA - PE: \\ APPROACH OF LANDSCAPE CONNECTIVITY
}

\author{
Joana D'arc Matias de Almeida ${ }^{1}$, Jonas Otaviano Praça de Souza ${ }^{2}$, Antônio Carlos de Barros \\ Corrêa'
}

${ }^{1}$ Universidade Federal de Pernambuco (UFPE), Recife, $P E$, Brasil

2 Universidade Federal da Paraíba (UFPB), João Pessoa, PB, Brasil

\author{
Correspondência para: Jonas Otaviano Praça de Souza (jonasgeoufpe@yahoo.com.br) \\ doi: $10.12957 /$ geouerj.2016.15456 \\ Recebido em: 6 mar. 2015 | Aceito em: 11 set. 2015
}

\section{SCREENED BY iThenticate $^{\circ}$}

\section{RESUMO}

A problemática da escassez de água no semiárido pernambucano incentiva pesquisas científicas visando a compreensão integrada do comportamento dos sistemas fluviais semiáridos, relacionando o sistema físico das bacias aos sistemas antrópicos. Nesta perspectiva o presente artigo buscou caracterizar a dinâmica fluvial da bacia do Riacho Grande, situada na microrregião do Pajeú, Sertão de Pernambuco, aplicando-se de forma integrada a proposta de conectividade da paisagem e de estilos fluviais, gerando informações básicas úteis para a gestão dos recursos hídricos em escala local. Para tanto, identificou-se a cobertura e usos do solo, a partir de dados obtidos em campo com o auxílio de GPS e uso de imagens QUICKBIRD e SRTM (Shuttle Radar Topography Mission); compreendendo sua dinâmica e relacionando-os à capacidade de infiltração da água retida no solo e ao escoamento superficial. O cálculo do volume de fluxo escoado deu-se por meio de dados extraídos a partir da plataforma de dados Agritempo - Embrapa, para o período de 1993-2012, através de Balanço Hídrico Sequencial Diário. Identificou-se na bacia do Riacho Grande três classes principais de uso da terra, associadas, junto à textura e estrutura do solo, ao volume de fluxo escoado na área. A análise identificou ainda os impedimentos de drenagem, capazes de reter o fluxo escoado impossibilitando-os de alcançar a rede de canais. Como principais impedimentos de transmissão foram identificados um grande número de barragens, estradas pavimentadas e não pavimentadas e planícies de inundação. Por fim também foi realizada a caracterização dos canais a partir da análise primária de estilos fluviais.

Palavras-chave: Conectividade da paisagem; Estilos fluviais; Sistema fluvial; Escoamento superficial; Recursos hídricos.

\begin{abstract}
The water scarcity problem in Pernambuco semiarid encourages scientific research that aim to understanding the behavior of integrated semiarid river systems, relating the physical system of basins to antropic systems. This perspective the present study characterized the fluvial dynamics of Riacho Grande basin, located in the Sertão de Pernambuco region, applying an integrated manner the proposal of landscape connectivity and rivers styles, generating useful background information for management of water resources at the local scale. Therefore, it was identified the land uses, from data obtained in the field work with the support of GPS and use of QuickBird and SRTM (Shuttle Radar Topography Mission) images; understanding its dynamics and relating them to water infiltration capacity retained in the soil and runoff. The calculation of runoff flow volume was performed by using data extracted from the Agritempo data platform, for the period 1993-2012, through water balance daily sequential. It was identified in the Riacho Grande basin 3 main classes of land use, associated, with the texture and soil structure, the volume of runoff flow in the area. The analysis also identified the drainage impediments, able to retain the drained flow making it impossible them from reaching the network channels. Between main transmission impediments was identified a large number of dams, roads paved and unpaved and floodplains. Finally, the characterization of the channels from the primary analysis of river styles.
\end{abstract}

Keywords: Landscape connectivity; Rivers styles; Fluvial system; Runoff; Water resources. 


\section{INTRODUÇÃO}

A escassez de reservas naturais de água e a irregularidade nas precipitações (VIEIRA, 2003) formam uma barreira à gestão dos recursos hídricos no semiárido brasileiro, resultando em medidas urgentes que funcionem como alternativas ao abastecimento de água na região. Diante deste contexto emergiram variadas pesquisas, técnicas e acadêmicas, que tentam oferecer suporte aos órgãos públicos e à população. Deste modo, é imprescindível compreender o comportamento dos sistemas fluviais semiáridos, relacionando o sistema físico das bacias hidrográficas aos sistemas antrópicos proporcionando um planejamento baseado nas características do sistema fluvial, não apenas restrito aos usos da água (SOUZA e CORREA, 2012), analisando a bacia hidrográfica como um sistema, assim trata-se de uma totalidade criada pela interação de um conjunto organizado de partes componentes (CHRISTOFOLETTI, 1999). Nessa linha, Bigarella, Suguio e Becker (1979) sinalizam a importância do conhecimento das características fluviais como um todo, não apenas no que se refere aos recursos hídricos, mas também nos pontos de vista sedimentológico, geomorfológico e de planejamento regional.

Considerando a bacia hidrográfica como objeto de planejamento, a mesma deve ser compreendida como um sistema aberto, que recebe energia por atuação dos agentes climáticos e tectônicos, e perde energia através da saída de água, sedimento e nutrientes. Assim, à guisa de exemplo, seriam considerados inputs, a precipitação, e outputs, os sedimentos erodidos (COELHO NETTO, 1998; SOUZA, 2013). Nesta perspectiva, o sistema fluvial compreende as zonas de produção, transporte e deposição de sedimentos, nas quais os sedimentos são estocados, erodidos e transportados em todas as zonas, porém em cada uma apenas um processo é dominante (SCHUMM, 1977). Além do conhecimento destes processos (erosão, transporte e deposição) é importante considerar seus fatores condicionantes/controladores, como os fatores climáticos e geológicos, envolvidos no suprimento de água e sedimento ao sistema fluvial, que por sua vez, assume o papel de agente modificador da superfície, por sua dinâmica, transportando fluxo de água e sedimentos em constante interação entre o canal e a encosta. 
No entanto, mudanças no regime do fluxo de água e sedimento, seja por tectônica ou por eventos hidrológicos, desestabilizam o sistema. Estes eventos tornam-se cruciais ao entendimento das variações do comportamento fluvial em terras secas (GRAF, 1988; SOUZA, 2011). Como fatorcontrole, a precipitação, afeta a natureza e a magnitude do trabalho geomorfológico na bacia de drenagem (COELHO NETTO, 1998; SOUZA, 2011), que para Graf (1988), estes detalhes presentes na superfície das terras secas são produtos da ação fluvial, embora o ambiente seco seja de escassez da precipitação, que funciona como um input de energia, resultando em diferentes formas e estruturas do sistema.

As características do fluxo e da carga de sedimentos, junto ao substrato geológico e à vegetação, exercem ação controladora sobre as formas dos canais (BIGARELLA, SUGUIO \& BECKER, 1979). Esses podem ser alterados ainda através do desenvolvimento de atividades antrópicas, como a intensificação da agricultura, implantação de barragens, extração mineral; contribuindo na escavação do leito, assoreamento e erosão nas planícies de inundação (SOUZA, 2011). Isto resulta em barramentos/impedimentos à montante e à jusante, que funcionam como elementos desconectantes em relação à transmissão de energia e matéria dentro do canal.

Nesta perspectiva insere-se a ideia de conectividade da paisagem, sendo essa a capacidade de transmissão de energia e matéria dentro do sistema fluvial. Para Fryirs (2013) é necessário o entendimento da dinâmica fluvial para enfim solucionar problemas relacionados ao transporte e deposição de sedimentos, contribuindo à gestão dos recursos hídricos em âmbito local. Os sedimentos são transportados, removidos ou estocados, quando em constante dinâmica podem ser erodidos e adicionados ao fluxo novamente, ou seja, os sedimentos podem ser retrabalhados (FRYIRS, 2013). Esta dinâmica é importante para entender como a conectividade se manifesta entre os compartimentos da paisagem, ora por contato físico, ora por transferência de energia e matéria entre compartimentos, até então desconectados. Esta (des)conectividade representa um fator de limitação quanto à eficiência nas relações de transferência de energia e matéria dentro do sistema (BRIERLEY, FRYIRS \& JAIN, 2006; FRIYRS, 2013). 
A análise da conectividade pode ser realizada a partir das interações entre os elementos de um sistema fluvial, elementos-chave às mudanças na superfície terrestre através do fluxo de água e sedimento, dando forma aos processos geomorfológicos, em diferentes escalas temporais e espaciais (BRIERLEY, FRYIRS, JAIN, 2006; SOUZA e CORREA, 2012). As diferentes escalas de conectividade da paisagem desencadeiam mudanças que influenciam a capacidade potencial do sistema recuperar-se após perturbação. Estas mudanças são provocadas por uma série de formas, que irão alterar a capacidade de transmissão do sistema, de forma a isolar setores e diminuindo a área de captação total da bacia (FRYIRS et al., 2007a). Assim, a análise de conectividade da paisagem permite identificar os elementos que influenciarão na transmissão de energia, ora impedindo e diminuindo o fluxo, ora incrementando-o (FRYIRS et al., 2007b; SOUZA e CORREA, 2012).

Assim, dentro do sistema fluvial, as ligações podem ser longitudinais, laterais e verticais; podendo ser rompidas por diferentes bloqueios, os buffers, barriers e blankets. As ligações laterais possuem relação entre a rede de canal e a ampla paisagem, incluindo as relações canal-encosta e canal-planície de inundação (floodplain). As encostas contribuem ao processo de retrabalhamento dos sedimentos para o canal. Já as ligações entre canal-planície de inundação estão relacionadas com a frequência e a magnitude dos eventos hidrológicos. Rompendo as ligações laterais, os buffers, são formas que atuam impedindo os sedimentos de adentrarem a rede de canais na bacia (BRIERLEY, FRYIRS \& JAIN, 2006; FRIYRS, 2013). As ligações longitudinais incluem, no contexto da rede de drenagem, as relações à montante e à jusante e da transmissão entre afluentes e rio principal, refletindo a capacidade de transporte de diferentes frações de sedimentos ao longo do curso. De modo a romper esta ligação, os barriers atuam sobre o nível de base ou leito do canal e são feições relativamente pontuais e frequentemente retrabalhadas. Os sedimentos estocados, em alguns casos, são transitórios e residem na paisagem durante curto período de tempo, em outros casos, são feições permanentes, que necessitam da ação dos eventos extremos para serem retrabalhadas (BRIERLEY, FRYIRS \& JAIN, 2006; FRIYRS, 2013). As ligações verticais, representam as interações superfície e sub-superfície de água e sedimento, sendo controladas pela textura do material e pelo regime de transporte do canal; assim segundo Fryirs (2013), estas ligações estão associadas às características dos solos e as relações entre o fluxo em superfície, sub-superfície e subterrâneo. Rompendo as ligações verticais, os 
blankets são feições que irão "sufocar" as demais feições, protegendo as formas do retrabalhamento e removendo temporariamente os sedimentos estocados (BRIERLEY, FRYIRS \& JAIN, 2006; FRIYRS, 2013).

Fryirs (2013) sugere que em condições ideais de bacia de drenagem, as forças das ligações longitudinais, laterais e verticais variam de acordo com a posição na bacia, no entanto, na realidade quaisquer posições ao longo dessas ligações podem gerar bloqueios, que influenciarão na dinâmica interna dos sedimentos na rede de drenagem. A partir desta perspectiva há necessidade de entender a bacia de drenagem como um sistema.

O presente artigo apresenta uma breve caracterização da dinâmica dos sedimentos na bacia do Riacho Grande (figura 01), com área de $316 \mathrm{~km}^{2}$, englobando parte dos municípios de Serra Talhada, Calumbi e Flores, no Sertão Pernambucano, através da abordagem conjunta entre o escoamento superficial e a conectividade da paisagem, como suporte para a gestão dos recursos hídricos em escala local. Para tal análise identificou-se as características físicas/ambientais da bacia, complementadas pela identificação do grau de confinamento dos vales fluviais a partir da proposta metodológica dos estilos fluviais, a fim de detalhar melhor os compartimentos da bacia e aplicá-los ao conceito de conectividade da paisagem, proporcionando um estudo integrado, oferecendo suporte à gestão de recursos hídricos e territoriais no semiárido pernambucano. As propostas de conectividade da paisagem e estilos fluviais são aplicáveis a qualquer ambiente, mas dada a importância da dinâmica fluvial nas terras secas, o presente trabalho utilizou-as como método de análise visando fornecer suporte aos estudos voltados ao planejamento no semiárido. 


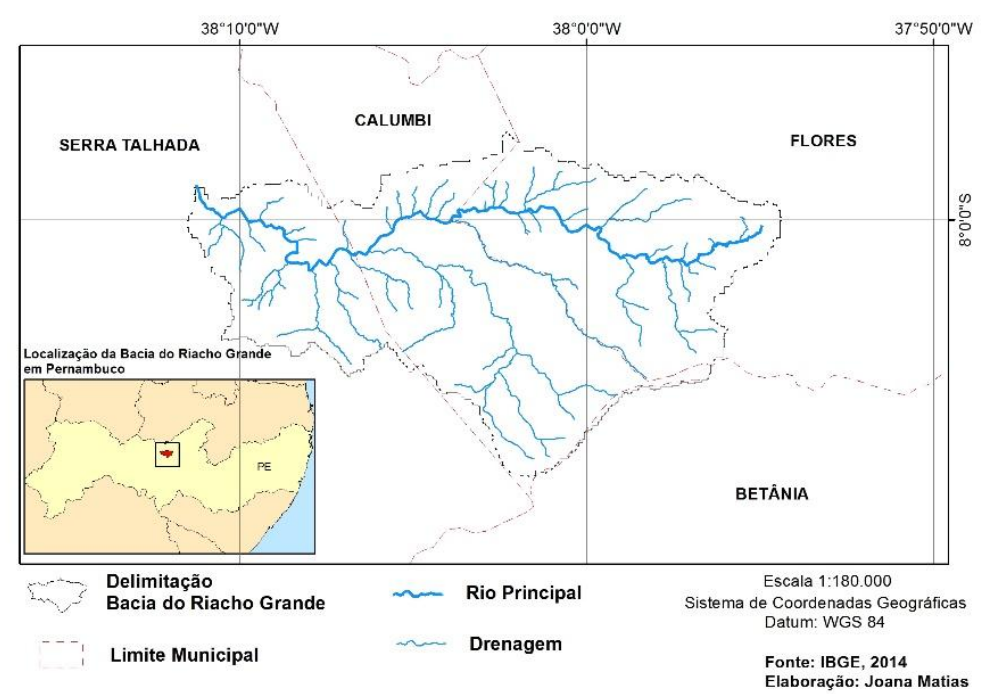

Figura 1. Localização da Bacia do Riacho Grande em Pernambuco.

MATERIAIS E MÉTODOS

Fonte: Elaborado pelos autores.

\section{Mapeamento do uso/cobertura da terra}

Para identificar a atual configuração do uso/ocupação da terra o presente trabalho utilizou como base dados de campo obtidos com o auxílio de GPS (GPS GarmimEtrexVistaHcx, e o GPS topográfico PRO-XH -Trimble), como também imagens QUICKBIRD atualizadas. Uma das especificidades foi o uso de imagens de diferentes períodos do ano 2013 (Junho/2013 e Setembro/2013), para que fosse possível identificar-se as diferenças intra-anuais de uso, como a relação cultura de ciclo curto, pasto e solo nu, que ocorre em grande parte das áreas utilizadas na região (SOUZA, 2011), focando nos usos que afetam diretamente elementos como infiltração, escoamento superficial e fornecimento de sedimento.

\section{Proposta Metodológica para o Escoamento Superficial}

A análise de escoamento superficial para a bacia do Riacho Grande foi realizada inicialmente a partir da coleta de dados pluviométricos (precipitação (mm), disponibilidade de água no solo e evapotranspiração potencial) da Plataforma de Coleta de Dados (PCD) do município de Calumbi (Latitude: $7^{\circ} 55^{\prime} 48.00^{\prime \prime S} /$ Longitude: $38^{\circ} 8^{\prime} 60.00^{\prime \prime S}$ ), obtidos através do projeto Sistema de 
Monitoramento Agrometeorológico - Agritempo, coordenado pela Embrapa. Apesar de não se localizar dentro da área da bacia, visto que não há no perímetro da mesma qualquer estação pluviométrica, a escolha dos dados do município de Calumbi, levou em consideração a frequência de dados na série histórica para os três municípios envolvidos nos limites da bacia, além do fator localização, por apresentar-se mais próxima do recorte da bacia do Riacho Grande, diminuindo erros devido a variação da precipitação a determinadas distâncias. Desta forma, os dados da PCD de Calumbi apresentaram-se mais adequados para a análise. Em seguida foi realizado o balanço hídrico sequencial diário (KARNIELLE \& ASHER, 1993; CHIEW et al., 1995) para o período de 1993 a 2012 . A análise diária da precipitação deu-se devido ao comportamento hidrológico irregular do Semiárido nordestino.

O escoamento superficial é resultado da interação entre a precipitação, os diferentes usos/cobertura da terra, bem como as características físicas (textura) do solo, influenciando a capacidade de infiltração de água. Logo, o cálculo de escoamento superficial pode ser obtido através de modelos de capacidade de infiltração, relacionando a precipitação e a disponibilidade atual de água no solo, limitada pela capacidade máxima de armazenamento de água em cada setor da bacia, de valores fixos de zona radicular média (Zr) (tabela 01), relacionada aos diferentes padrões de uso da terra e a textura dos solos, a qual se atribuiu valores de CAD médio - capacidade média de água disponível no solo (tabela 02), relacionados à porosidade dos solos.

Tabela 1. Valores de Zr média para cada padrão de uso na bacia do Riacho Grande.

\begin{tabular}{lc}
\hline Uso/Cobertura do Solo & Zona Radicular Média (Zr) em cm \\
Caatinga conservada & 100 \\
Caatinga Degradada & 50 \\
Uso misto & 40 \\
\hline
\end{tabular}

Fonte: Adaptado de Alfonsi et al., 1990.

Tabela 2. Valores de CAD médio para solos arenosos, argilosos e de textura média na bacia do Riacho Grande.

\begin{tabular}{lc}
\hline Textura dos Solos & CAD médio $(\mathrm{mm} / \mathrm{cm})$ \\
Arenoso & 0,6 \\
Argiloso & 2,0 \\
Textura média & 1,4 \\
\hline
\end{tabular}


Assim, permite-se definir a capacidade de campo ou capacidade máxima de água disponível no solo (CAD máximo), por meio da relação entre as duas variáveis (Zr média x CAD médio), utilizando o cálculo de álgebra de mapas, do software ArcGis 10, através da ferramenta Raster Calculation. No software, as informações anteriores de uso e ocupação da terra e textura de solo foram transformadas em arquivos Raster, e posteriormente atribuíram-se os valores fixos para cada classe, como demonstrado nas tabelas 01 e 02. Assim, definidos os valores de CAD máximo para cada área da bacia e junto aos dados gerados no balanço hídrico sequencial diário, estima-se o volume escoado, para posteriormente, junto à análise da conectividade da paisagem, mensurar o quanto de água ficará retido devido aos impedimentos de drenagem.

\section{Mapeamento de conectividade da paisagem}

O mapeamento da conectividade da paisagem consistiu em identificar os elementos que influenciam na transmissão de energia e matéria dentro do sistema, tanto impedindo e/ou diminuindo o fluxo quanto o incrementando (FRYIRS, BRIERLEY, et al., 2007). Esses elementos foram divididos em quatro tipos; buffers, barriers, blankets e boosters (FRYIRS, BRIERLEY, et al., 2007). A identificação dos elementos desconectantes foi realizada, inicialmente a partir das informações de declividade, geomorfológicas e do mapeamento de uso da terra (FRYIRS, BRIERLEY, et al., 2007), além da utilização de imagens QUICKBIRD e informações coletadas em campo.

\section{Mapeamento de Estilos Fluviais}

A partir do cenário de mudanças nos ambientes fluviais, a proposta teórico-metodológica de estilos fluviais fornece, em escala de detalhe, um modelo coerente para atividades de gestão dos recursos hídricos, entendo o comportamento e evolução do sistema fluvial. Os estilos fluviais aplicados aos programas de planejamento ambiental observam a capacidade do sistema e possibilidades de recuperação, conservando estilos raros e mantendo a diversidade das paisagens fluviais (FRYIRS \& BRIERLEY, 2009; SOUZA, 2014). 
Na proposta de estilos fluviais, a bacia hidrográfica funciona como um conjunto próprio de atributos, analisados através da planta do canal, das unidades geomórficas da bacia e da textura do leito do rio (BRIERLEY \& FRYIRS, 2005). Conforme Corrêa et al. (2009) "a identificação e interpretação das unidades geomórficas possibilita a interpretação dos processos que refletem a dimensão do comportamento dos estilos fluviais". Sendo assim, os estilos fluviais são analisados considerando o seu contexto paisagístico e as ligações espaciais e temporais dos seus processos geomorfológicos (CORRÊA et al., 2009; SOUZA, 2014).

Esta abordagem fornece um conjunto de informações integradas para a compreensão das formas, processos e ligações nos canais fluviais, oferecendo uma base para a previsão futura do comportamento fluvial (BRIERLEY \& FRYIRS, 2005). Desta maneira, a análise dos estilos fluviais compõe-se de quatro etapas. A primeira envolve a identificação, interpretação e mapeamento dos estilos fluviais em uma bacia hidrográfica. Esta etapa é a base para o início dos estudos das características do comportamento fluvial. As avaliações do caráter e do comportamento fluvial devem ser dinâmicas, e as formas e os processos são avaliados no contexto de evolução do sistema fluvial, nesta perspectiva insere-se a segunda etapa. A terceira corresponde à avaliação da trajetória futura das mudanças e potencial de recuperação do canal fluvial, enquanto no estágio 4 sugere-se as aplicações para a gestão fluvial (BRIERLEY \& FRYIRS, 2005).

De tal modo, no presente trabalho, o mapeamento de estilos fluviais foi realizado de forma simplificada, com o objetivo de apresentar os tipos de canais presentes na área. E para tal finalidade, adaptou-se a metodologia utilizada por Brierley \& Fryirs (2005), considerando a declividade da área, a geomorfologia, o uso/cobertura da terra. Utilizou-se inicialmente imagens QUICKBIRD para o reconhecimento dos padrões de drenagem e posteriormente a análise em campo para confirmação dos trechos mapeados. Sendo assim, o mapeamento dos estilos fluviais na bacia do Riacho Grande considerou a primeira etapa da análise dos estilos, que avalia o caráter e comportamento de cada trecho do rio (BRIERLEY \& FRYIRS, 2005; SOUZA, 2014). Nesta etapa, os estilos fluviais são identificados a partir do confinamento do vale. 
Portanto, através das imagens QUICKBIRD identificou-se os trechos dos canais fluviais com a presença de planícies de inundação, determinando a configuração do vale em cada trecho, podendo o canal ser confinado (quando menos de 10\% do trecho apresenta extravasamento do fluxo - planície de inundação), parcialmente confinado (quando entre 10 a $90 \%$ do trecho apresenta planície de inundação) e não-confinado ou lateralmente não-confinado (quando mais de $90 \%$ do trecho apresenta planície de inundação) (BRIERLEY \& FRYIRS, 2005). Além da configuração do vale, considerou-se a sinuosidade do canal, a morfologia do vale e as unidades geomórficas presentes na área, definindo-se por fim os estilos fluviais presentes na bacia.

Como resultado espera-se construir um quadro de informações apresentando as características do rio, comportamento e controles, sendo possível identificar os trechos representativos do canal, para então analisar a capacidade de ajuste por cada trecho (SOUZA, 2012). Brierley e Fryirs (2005) têm como questão norteadora para análise dos estilos fluviais, a proposta de que é necessária uma restauração/reabilitação dos rios, se possível retornando-os às suas condições fluviais iniciais, ou à criação de um cenário mais próximo possível do ambiente original. Portanto, a metodologia de estilos fluviais fornece aparato para a construção de metas e cenários futuros visando a gestão dos recursos hídricos e a reabilitação dos ambientes fluviais.

\section{RESULTADOS}

\section{Escoamento Superficial e Conectividade da Paisagem}

O mapeamento do uso da terra da bacia do Riacho Grande (figura 02) foi uma das primeiras etapas para predizer o impacto dos diferentes usos na dinâmica fluvial da bacia através da proposta baseada na influência de cada classe encontrada na capacidade de infiltração de água e escoamento superficial. Deste modo, foram identificadas 3 classes principais de uso: vegetação conservada (28,4\%), vegetação em estágio de degradação $(38,3 \%)$ e uso misto (33,3\%), neste último encontram-se agrupados as áreas destinadas à pecuária e ao uso agrícola com modificações intra-anuais, como o plantio de mandioca, milho e feijão, e também com períodos de pousio e solo nu. 


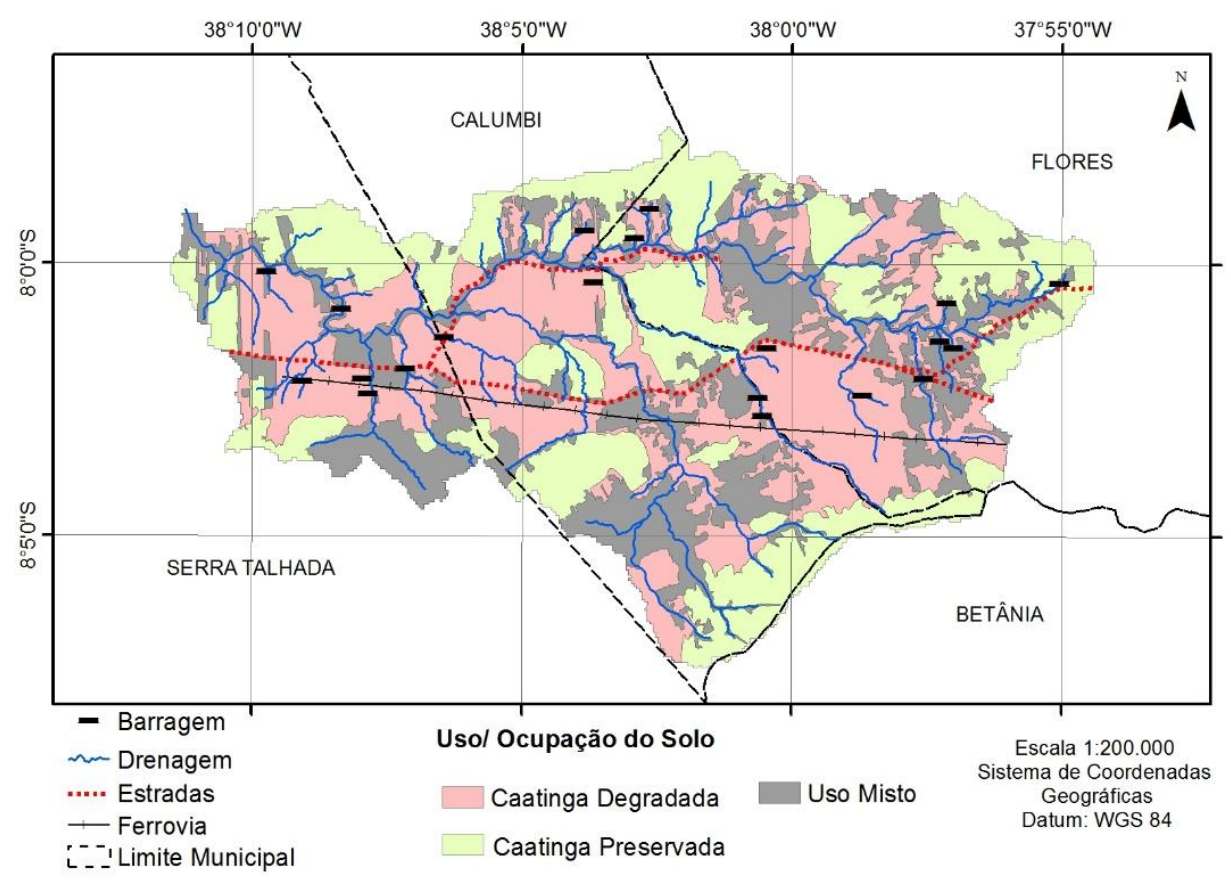

Figura 1. Mapeamento de uso da terra da Bacia do Riacho Grande, Serra Talhada, PE.

Fonte: Elaborado pelos autores.

O uso/cobertura da terra está relacionado diretamente ao desempenho dos solos, verificando-se que 0 aumento da capacidade de armazenamento de água depende da textura e da estrutura do solo. Assim, foi realizado a espacialização dos solos presentes na bacia (figura 03), a partir do qual será identificado as informações necessárias para a análise do escoamento.

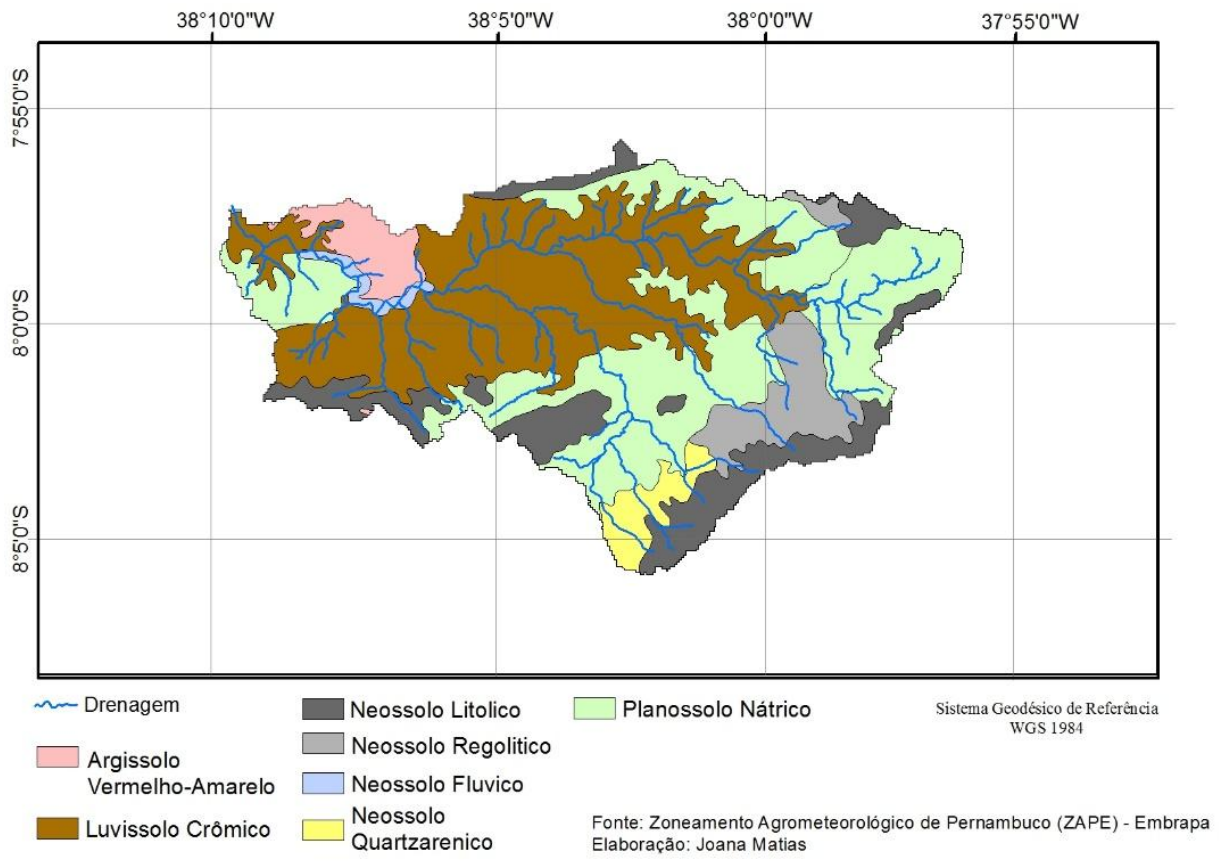

Figura 3. Mapa de solos na Bacia do Riacho Grande, Serra Talhada, PE.

Fonte: Elaborado pelos autores. 
Dentre as classes de solo presentes na bacia, conforme a figura 03, destaca-se a classe dos neossolos, definida como um agrupamento de subordens constitui-se de solos pouco desenvolvidos, de material mineral ou orgânico pouco espesso. Encontra-se na área neossolos litólicos (13,8\% da área da bacia), apresentando fragmentos de rocha na fração cascalho, caracterizando-se por serem solos rasos e pouco evoluídos, estando presentes nas áreas de alta declividade, caracterizadas pelas superfícies de morros e serras baixas e escarpadas. Sobre esta classe de solos, a cobertura da terra caracteriza-se pela ocorrência de vegetação ainda em sua maior parte preservada e, em menor proporção o uso misto, destinado principalmente à pecuária. Os neossolos flúvicos (1,13\%), derivados de sedimentos aluviais, possuem granulometria variada, e estão presente nas margens do canal principal, em terreno de baixa declividade, proporcionando o desenvolvimento de atividades agropecuárias; os neossolos regolíticos $(6,84 \%)$ apresentam textura arenosa ou média de baixo teor de argila, sendo mais comuns os teores de silte presente nas áreas de terreno suave ondulado ou plano, enquanto os neossolos quatzarênicos $(3,08 \%)$ formam-se sobre os sedimentos arenosos cenozóicos e arenitos da Bacia do Jatobá (EMBRAPA, 2006).

Os luvissolos crômicos (36,9\%), que ocorrem em regiões de limitação hídrica, são constituídos de material mineral com argila de alta atividade e alta saturação por bases sendo mais susceptíveis à compactação (EMBRAPA, 2014). Estes são representados por uma área de maior degradação da vegetação, principalmente para o desenvolvimento de culturas temporárias, neste setor predominam terrenos de baixa declividade, correspondentes às superfícies aplainadas do Complexo São Caetano. Os argissolos vermelho-amarelos $(3,75 \%)$ estão representados em menor extensão na área da bacia, onde a vegetação permanece conservada, estes solos são constituídos de material mineral com horizonte textural composto de argila de alta a baixa atividade (EMBRAPA, 2006). Os planossolos nátricos $(34,5 \%)$, solos rasos a pouco profundos, têm baixa permeabilidade e são muito susceptíveis à erosão. Esses localizam-se geralmente nos terraços de rios e riachos e em áreas de topografia suave. A vegetação de caatinga se desenvolve neste solo, porém na maioria das áreas onde esta classe de solo foi identificada, a vegetação encontra-se degradada e/ou com exposição do solo para o desenvolvimento de atividades agropecuárias (EMBRAPA, 2014). 
Além das características pedológicas, a cobertura vegetal mantém relação também com o escoamento superficial, quando degradada contribui ao aumento do escoamento, e quando preservada o processo é retardado, pelo fato da vegetação formar uma camada de proteção. As águas que fluem sobre o solo exposto encontram-se carregadas de material desagregado (silte e argila) que tende a se depositar na porosidade do solo, compactando-o (BIGARELLA \& SUGUIO, 1979). Enquanto isso, solos com cobertura vegetal preservada aceleram o processo de infiltração através da distribuição das raízes das plantas.

O cálculo da capacidade de água disponível no solo realizado por meio do software ArcGis 10, e baseado em trabalhos de Alfonsi (1990) e Souza (2014), resultou na geração de 8 valores de CAD máximo, agrupados em 4 valores de maior expressão na bacia: $30 \mathrm{~mm}, 80 \mathrm{~mm}, 100 \mathrm{~mm}$ e $200 \mathrm{~mm}$ (figura 04).

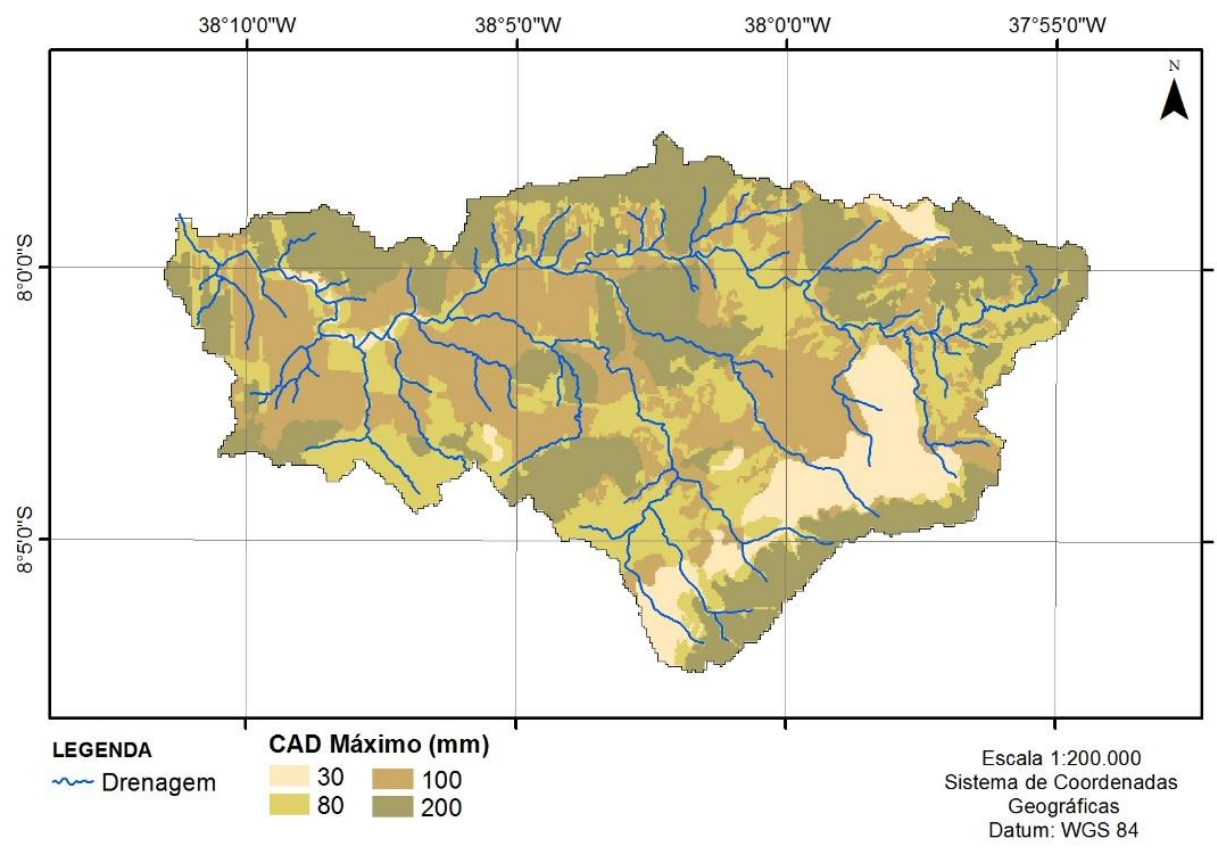

Figura 4. Valores de CAD máximo (mm) para a bacia Riacho Grande, Serra Talhada-PE. Fonte: Elaborado pelos autores.

Estes valores de CAD máximo distribuem-se em relação inversa ao escoamento superficial, à medida que quanto maior o CAD máximo, maior será a capacidade de infiltração da água no solo, enquanto que os menores valores estão em áreas mais propensas ao escoamento superficial. Deste modo, observando os dados presentes na tabela 03, verificou-se que na bacia do Riacho Grande as áreas de 
CAD $200 \mathrm{~mm}$ possuem a vegetação preservada e solos predominantemente arenosos, portanto apresentaram menores volumes de fluxo escoado (8,8\% do volume total). Por outro lado, nas áreas de CAD $30 \mathrm{~mm}$ predominam solos de textura média, com volume escoado razoável considerando-se a sua espacialização na bacia (25,9\%). O CAD $80 \mathrm{~mm}$ apresentou maior volume escoado (33,9\%) e representa áreas com predominância de superfícies degradadas pelo desenvolvimento de atividades antrópicas.

Tabela 3. Volume de CAD máximo - Bacia do Riacho Grande, Serra Talhada-PE.

\begin{tabular}{|cccccccc|}
\hline CAD & Area $(\mathbf{k m 2})$ & Area $(\%)$ & Total $(\mathbf{m m})$ & Total $(\boldsymbol{\%})$ & \multicolumn{2}{c|}{ Volume $\left(\mathbf{m}^{\mathbf{3}}\right)$} & Volume $(\boldsymbol{\%})$ \\
\hline 30 & 30,3 & 9,59 & 4231,4 & 46,06 & 128168440,5 & 25,9 \\
\hline 80 & 85,4 & 27,03 & 1968,7 & 21,43 & 168174998 & 33,9 \\
\hline 100 & 101,6 & 32,15 & 1529,7 & 16,65 & 155441757,3 & 31,4 \\
\hline 200 & 96,5 & 30,54 & 442,9 & 4,82 & 43624375,15 & 8,8 \\
\hline
\end{tabular}

Fonte: Elaborado pelos autores.

Porém, o volume do fluxo escoado é retido por uma série de impedimentos de transmissão de energia e matéria dentro do sistema, que funcionam como elementos desconectores. Os impedimentos caracterizam-se por: planícies de inundação, barragens, estradas pavimentadas e não pavimentadas, e ferrovias (figura 05).

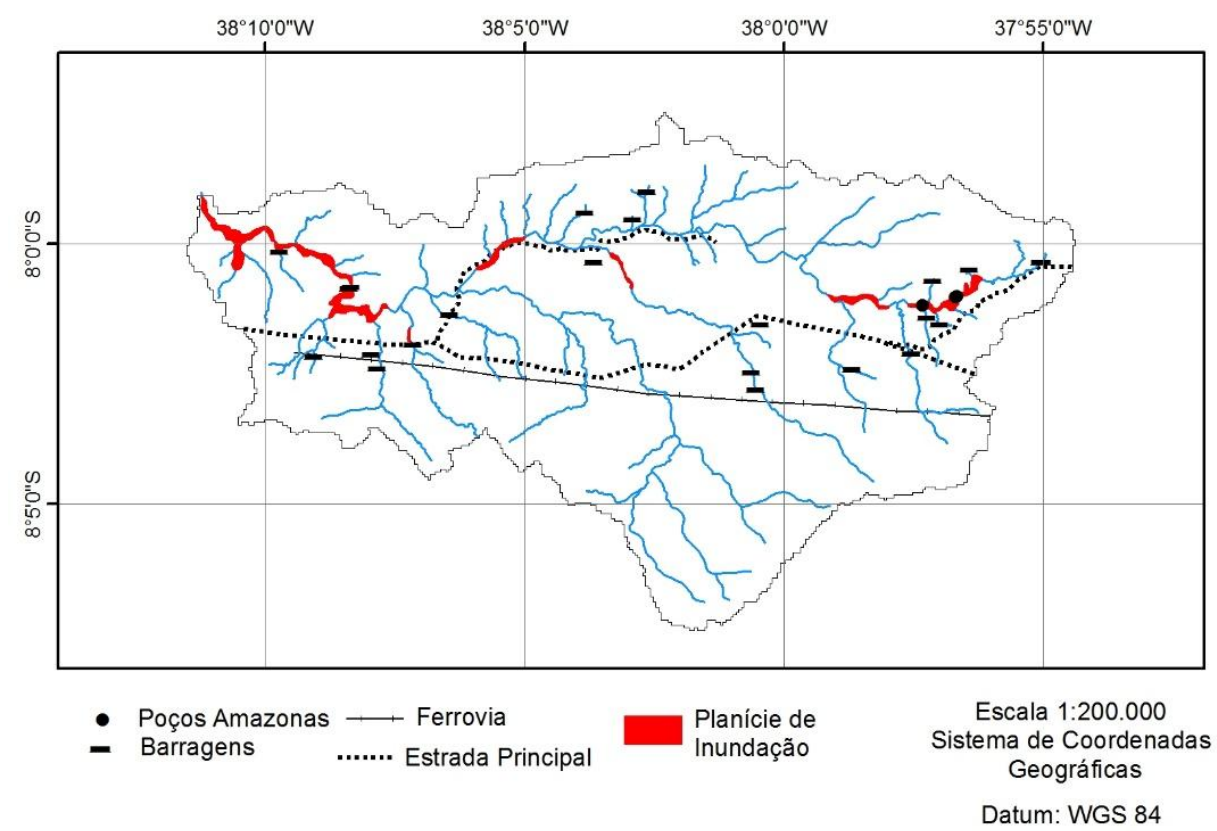

Figura 5. Impedimentos de transmissão na Bacia do Riacho do Grande, Serra Talhada-PE. Fonte: Elaborado pelos autores. 
Notou-se, principalmente, a grande quantidade de barragens (figura 06) ao longo da bacia do Riacho Grande, constituindo-se como as formas de impedimento responsáveis pelas maiores alterações nos processos de transmissão dentro da bacia. Essas atuam como impedimentos longitudinais (barriers) impedindo o fluxo de circular livremente por entre os compartimentos da paisagem.

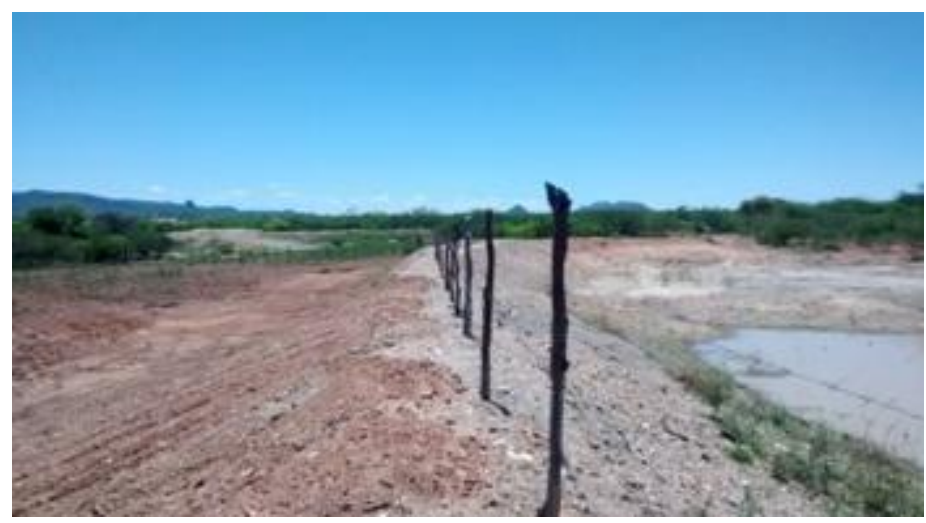

Figura 6. Barragem de terra.

Fonte: Elaborado pelos autores.

A construção destas barragens dá-se pela necessidade de medidas alternativas de abastecimento de água para a manutenção das lavouras e para pecuária. Por se tratarem de modelos simples, sem o devido aparato estrutural e tecnológico, são bastante comuns durante os eventos chuvosos de alta magnitude os rompimentos destas barragens, alterando o cenário de conectividade dentro da bacia.

Entre os impedimentos laterais (buffers), as estradas, sejam pavimentadas ou não (figura 07), atuam impedindo que o fluxo de sedimentos alcance a rede de canais. Durante eventos de baixa magnitude, em que o fluxo não tem competência suficiente para ultrapassá-las, o sedimento fica retido nas laterais da estrada, ou segue-a paralelamente modificando a rede de canais.

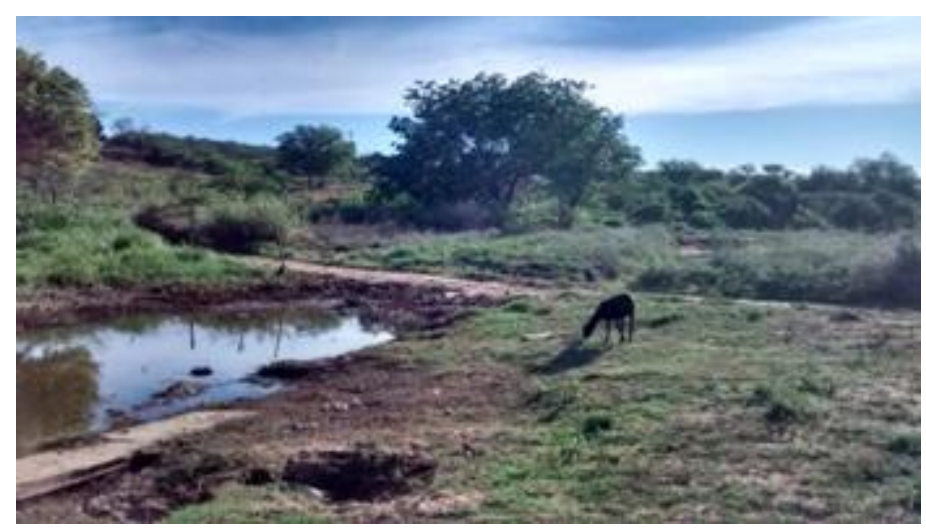

Figura 7. Estrada não pavimentada como elemento de desconexão. 
Fonte: Elaborado pelos autores.

Também atuando como buffer, as planícies de inundação, são responsáveis pela retenção do fluxo escoado dentro da bacia, constituindo-se como fonte alternativa de abastecimento de água, através do fluxo retido em sub-superfície, nestes casos é comum a perfuração de poços rasos.

Devido à distribuição destes impedimentos em todo o sistema, dividiu-se a bacia do Riacho Grande em sub-bacias para a identificação do volume escoado retido de forma direcionada. Nota-se que de 10\% a $40 \%$ do volume total escoado na bacia fica retido devido à considerável quantidade de elementos desconectantes (figura 08), que impedem o fluxo de alcançar o canal principal, exceto quando a água infiltra alcançando o canal fluvial como fluxo de base.

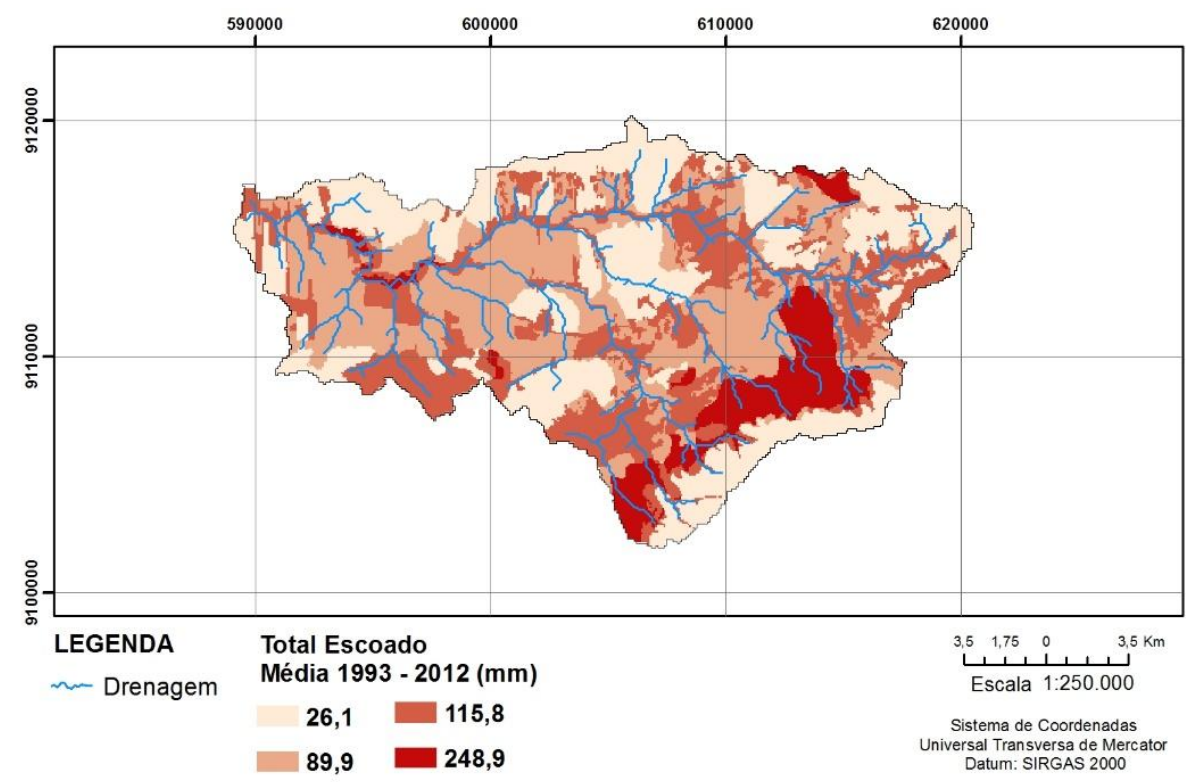

Figura 8. Volume escoado (\%) por sub-bacias - Bacia do Riacho Grande, Serra Talhada, PE. Fonte: Elaborado pelos autores.

A sub-bacia $J$ apresenta maior percentual de fluxo escoado retido (30-40\%). Este fato se dá pela quantidade de elementos de desconexão na sub-bacia, que apresenta em sua distribuição um grande número de barragens e extensas áreas de planícies com inundação. A sub-bacia E, de solo predominantemente arenoso, apresenta em média de 5-10\% de fluxo escoado, apresentando-se dentro da área de CAD entre 80 a $200 \mathrm{~mm}$, e prevalecendo, neste caso, o processo de infiltração. 
Nos ambientes com vegetação degradada ou ausente predomina o processo de escoamento superficial, enquanto que em áreas de vegetação densa e conservada e de solos arenosos prevalece o processo de infiltração da água de precipitação no solo, contribuindo à manutenção do regime dos canais fluviais. 0 fluxo escoado é retido pelos impedimentos de transmissão espacializados na bacia, impossibilitando a interação de energia e matéria entre compartimentos da paisagem.

\section{Configuração dos Canais Fluviais na Bacia do Riacho Grande}

A proposta de estilos fluviais foi aplicada de maneira simplificada para a bacia do Riacho Grande com o objetivo de identificar a configuração dos canais fluviais, e com base nos pontos de controle verificados em campo confirmar o grau de confinamento do vale. Assim, na bacia do Riacho Grande foram identificados trechos de canais confinados, parcialmente confinados e não confinados (figura 09).

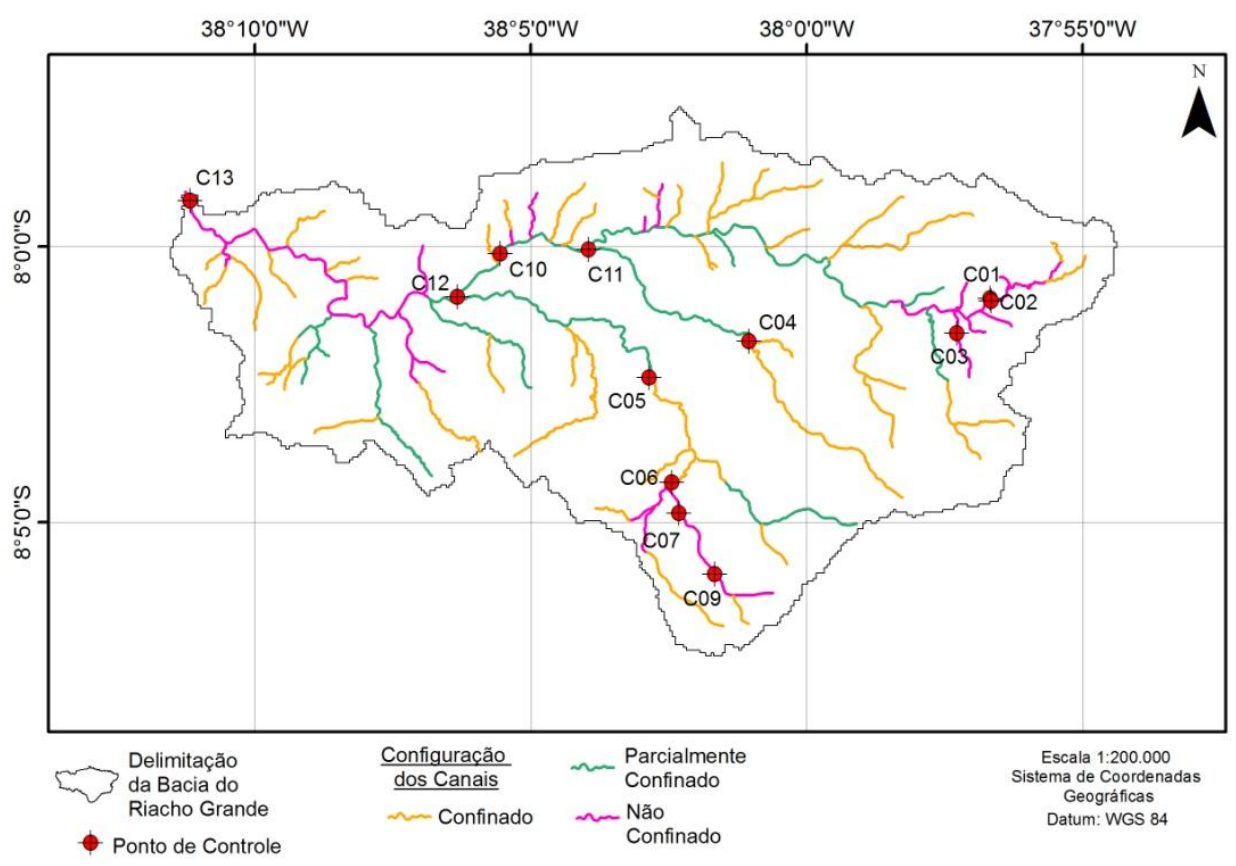

Figura 9. Configuração dos canais na bacia do Riacho Grande.

Fonte: Elaborado pelos autores.

\section{Trecho Confinado}


O trecho de canal confinado ( $<10 \%$ apresenta planícies de inundação) foi representado pelo ponto $\mathrm{C} 05$ (figura 10). Classificado como canal rochoso com planície de inundação descontinua.

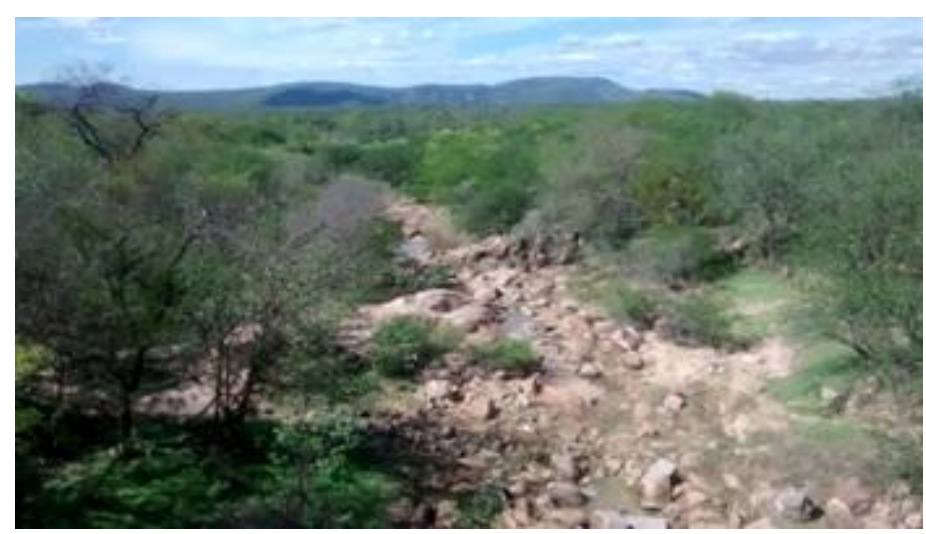

Figura 10. Canal rochoso com planície de inundação descontínua. Fonte: Elaborado pelos autores.

Este trecho apresenta leito rochoso, com a predominância de metagranitóides do Complexo São Caetano. Apresenta-se confinado em baixa declividade, com encostas suave-onduladas, e apresenta média sinuosidade. Nos trechos de vale confinado predomina a caatinga em estágio de degradação e uso misto, o que contribui ao escoamento superficial, com volume médio escoado de $15-20 \%$ no ponto C05.

\section{Trecho Parcialmente Confinado}

Os trechos de vale parcialmente confinados foram verificados através dos pontos C04, C10 (figura 11), C11 e C12 (figura 12). Estes trechos caracterizam-se pela presença de planícies de inundação descontinuas (10-90\% do trecho), sinuosidade de média a baixa, e estão localizados em baixa declividade.

Nos trechos em questão predomina o desenvolvimento de atividades agropecuárias, sobretudo a criação de bovinos, suínos e caprinos. Para esta prática utiliza-se o pasto natural e têm-se a modificação do terreno com a instalação de cercas e abertura de pequenas estradas, caracterizando-se como impedimentos de drenagem. 


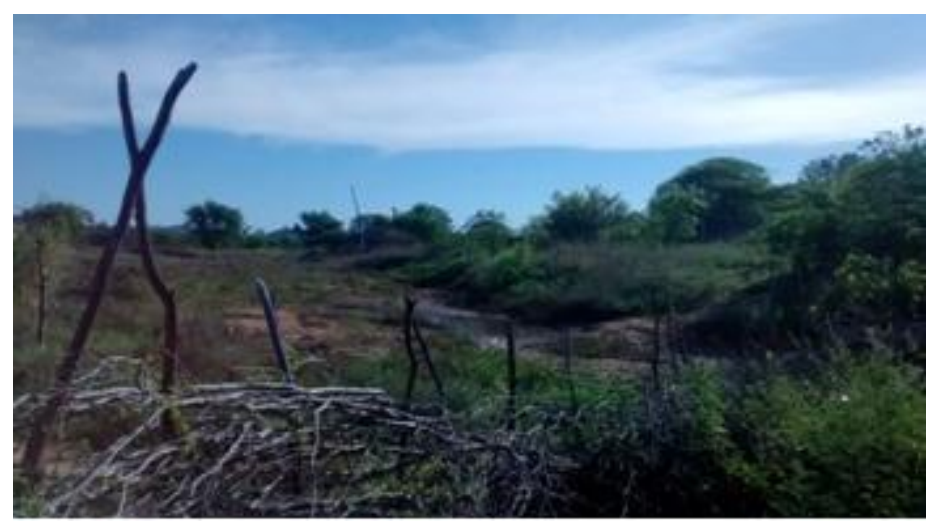

Figura 11. Ponto C10 - canal escavado após cerca. Fonte: Elaborado pelos autores.

Na maior parte dos trechos parcialmente confinados, tem-se a escavação do leito para a perfuração de poços amazonas para obtenção de água para fins domésticos, irrigação e desedentação animal, como na área próxima a confluência no ponto $\mathrm{C} 11$. Em outros trechos parcialmente confinados, os canais apresentam leito rochoso, como no ponto C12 (figura 12).

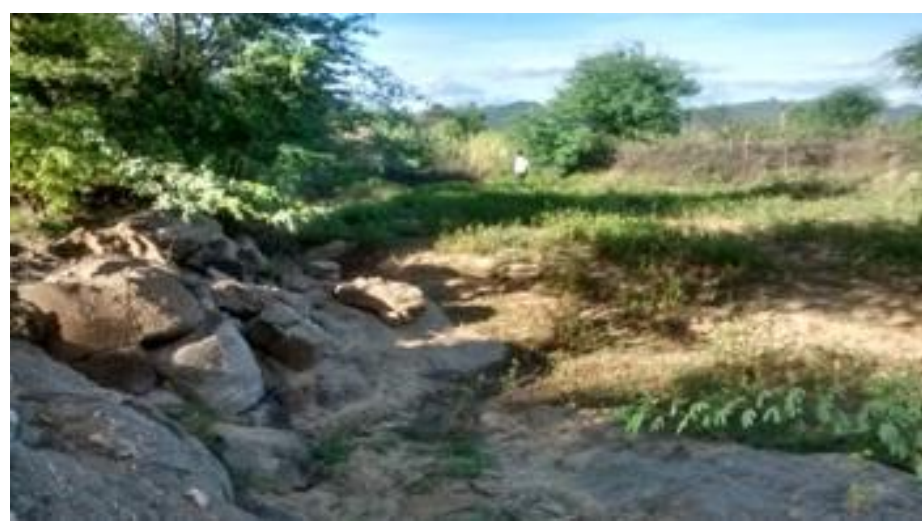

Figura 12. Ponto C12 - canal de leito rochoso próximo a confluência do rio principal e rio da Varzinha. Fonte: Elaborado pelos autores.

\section{Trecho Não Confinado}

Os trechos de vale não confinados ( $>90 \%$ apresentam planícies de inundação) caracterizam-se por extensas áreas de depósitos sedimentares, ou seja, extensos vales aluviais, em baixa declividade e de relevo plano a suave-ondulado, e média sinuosidade, com a predominância de áreas para a criação de animais de pequeno a médio porte, e o desenvolvimento agrícola para consumo familiar. 
No ponto C02 (figura 13) a ocorrência de diferentes patamares representa distintos eventos de deposição. De solo arenoso, o patamar mais alto representa o antigo curso fluvial, e o patamar mais baixo, o atual curso do rio durante eventos chuvosos que propiciam a ocorrência de drenagem na área.

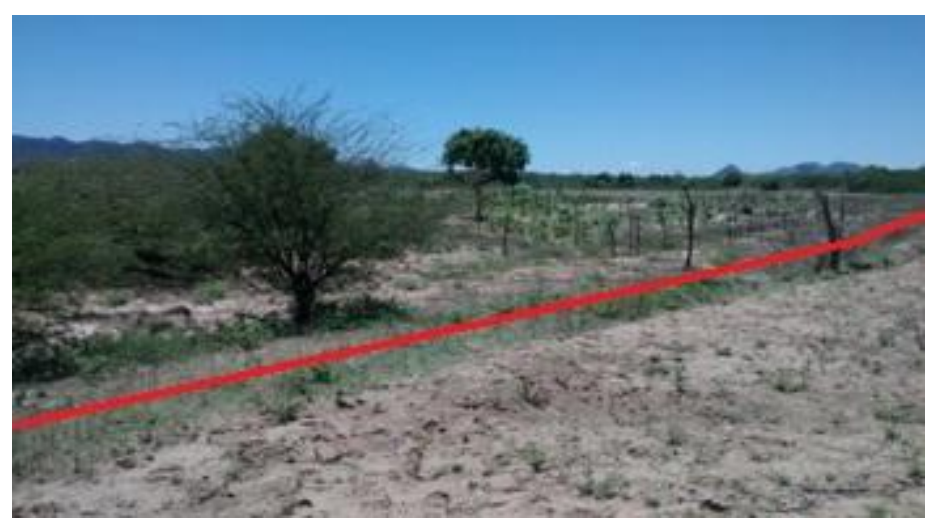

Figura 13. Ponto C02 - canal aluvial (diferença de patamares). Fonte: Elaborado pelos autores.

Largos plainos preenchidos são destacados nos trechos não confinados (ou lateralmente não confinados). Nestes plainos comumente são encontrados poços amazonas perfurados em leito arenoso, com profundidade média de 3 a 7m, sendo estes escavados até atingir a rocha-sã (figura 14).

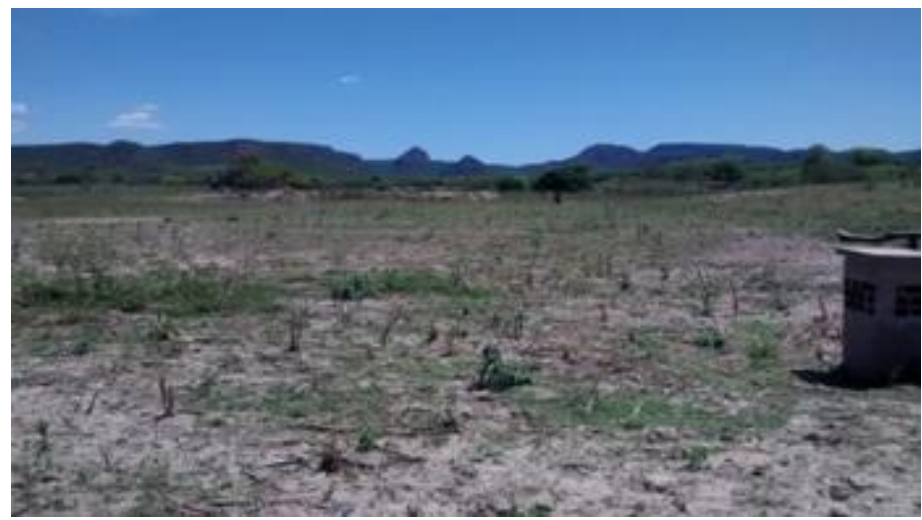

Figura 14. Ponto C03 - plaino aluvial preenchido com poço amazonas (profundidade $4.50 \mathrm{~m}$ ). Fonte: Elaborado pelos autores.

As estradas não pavimentadas e as barragens (figura 15) funcionam como barramento nos trechos dos canais descontínuos e de leito arenoso. Os barramentos impedem o fluxo escoado de circular entre os compartimentos da paisagem, acumulando sedimentos nos terrenos de baixa declividade durante os eventos de alta magnitude. 


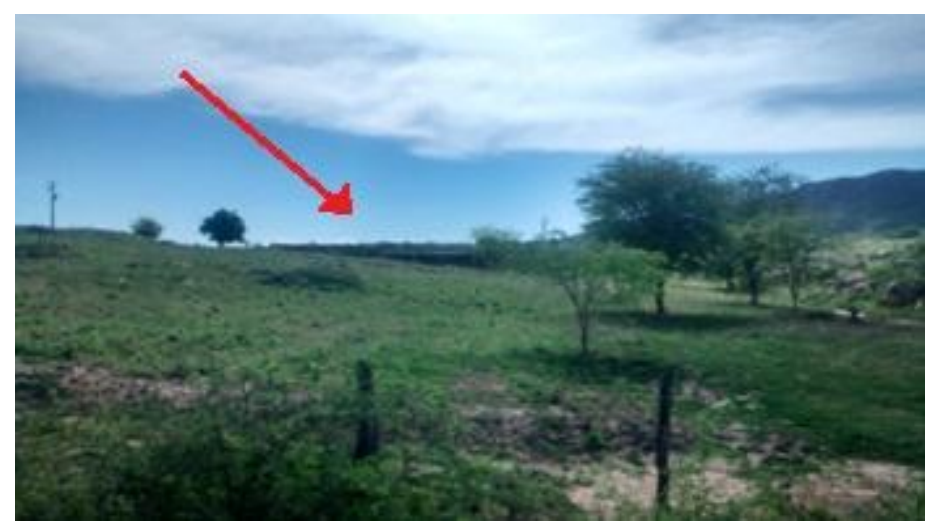

Figura 15. Ponto C6 - barragem (destaque) no canal descontínuo de leito arenoso. Fonte: Elaborado pelos autores.

Nestes trechos o fluxo escoado varia em porcentagem de 5-30\%, predominando o processo de infiltração devido à alta permeabilidade e porosidade dos solos predominantemente arenosos.

\section{CONSIDERAÇÕES FINAIS}

A dinâmica fluvial no que tange os processos de produção, transporte e deposição de sedimentos em uma bacia fluvial é de conhecimento fundamental e constitui análise a priori na fundamentação de projetos relacionados aos planejamentos hídrico, ambiental e territorial.

Os resultados obtidos neste trabalho levaram ao conhecimento da dinâmica fluvial na bacia do Riacho Grande, considerando os aspectos físicos e antrópicos nos processos fluviais. Pode-se considerar deste modo, que a área em análise apresentou um cenário de modificação e degradação da paisagem natural através do desenvolvimento de atividades voltadas à agricultura e pecuária. Estas atividades impulsionam os processos erosivos nas encostas, nas margens e no leito dos rios, alterando a dinâmica do sistema fluvial.

As modificações puderam ser constatadas através da quantidade de impedimentos de drenagem na paisagem, o que inibe o fluxo de energia e matéria de circular livremente entre os compartimentos do sistema. Um desses impedimentos é caracterizado pela construção de barragens, que retém o fluxo 
escoado, formando uma barreira impossibilitando o mesmo de alcançar o canal principal. Além das aberturas de estradas não pavimentadas, que alteram a direção natural do fluxo.

Outra forma de impedimento foram as áreas de largas planícies de inundação, em que os plainos encontram-se preenchidos e com grande número de poços amazonas escavados, com profundidade variável, armazenando a água em sub-superfície nos eventos de maior magnitude.

A identificação primária dos estilos fluviais através do grau de confinamento do vale sugere a aplicabilidade da metodologia às regiões semiáridas, sobretudo se associadas à identificação de depósitos aluviais para a perfuração e instalação de poços rasos. Devido ao alto número desses na área da bacia do Riacho Grande, aponta-se os mesmos como uma potencial fonte alternativa de abastecimento de água na região, indicando um estudo mais detalhado destes depósitos através do mapeamento geoquímico, de modo a verificar a qualidade da água armazenada em sub-superfície.

No geral, o trabalho apresentou resultados positivos quanto a aplicação das propostas de conectividade da paisagem e estilos fluviais às áreas semiáridas, sobretudo reconhecendo a importância destas abordagens atreladas ao planejamento territorial e de recursos hídricos, apesar das dificuldades encontradas no desenvolvimento do trabalho devido à precariedade de dados meteorológicos precisos recobrindo a área em análise.

\section{Agradecimentos}

Agradecimento à Fundação de Amparo a Ciência e Tecnologia do Estado de Pernambuco (FACEPE) pela concessão de bolsa de mestrado ao primeiro autor deste artigo.

\section{REFERÊNCIAS}

ALFONSI, R. R. et al. Métodos agrometeorológicos para controle da irrigação. Campinas: InstitutoAgronômico, 1990.62 p. 
BRIERLEY, G.; FRYIRS, K. Geomorphology and river management: applications of the river styles framework. Blackwell Publishing. 2005. 398 p.

BRIERLEY, G.; FRYIRS, K. Geomorphology and river management: applications of the river styles framework. Blackwell Publishing. 2005. Resenha de: SOUZA, J. O. P. Geomorphology and river management: applications of the river styles framework. Revista de Geografia, v. 29, n. 2, 2012.

BRIERLEY, G.; FRYIRS, K.; JAIN, V. Landscape connectivity: the geographic basis of geomorphic applications. Area, v. 38 , n. 2, p.165-174, 2006.

Bigarella, J. J.; SUguio, K.; BeCKeR, R. D. Ambiente Fluvial. Curitiba: Ed. Universidade Federal do Paraná, 1979. 172p.

CHIEW, F. H. S. et al. Simulation of the impacts of climatic change on runoff and soil moisture in Australian catchments. Journal of Hidrology, n. 167, p. 121-147, 1995.

CHRISTOFOLETTI, Antonio. Modelagem de Sistemas Ambientais. São Paulo: Ed. Blucher, 1999. p.236.

COELHO NETTO, A. L. Hidrologia de encosta na interface com a geomorfologia. In: GUERRA, A. J. T.; CUNHA, S. B. Geomorfologia: uma atualização de conceitos e bases. Rio de Janeiro: Bertrand Brasil, 1998. p. 93-148.

CORRÊEA, A.C.B. et al. Estilos fluviais de uma bacia de drenagem no submédio São Francisco. Revista de Geografia, v. 26, n. $1,2009$.

DOOREnGOS, J.; KASSAM, A. H. Efeito da água no rendimento das culturas. Campina Grande: UFPB, 1994.

EMBRAPA. Manual de Métodos de Análise de Solo. $2^{\text {a }}$ ed. Rio de Janeiro, 1997.

EMBRAPA. Sistema Brasileiro de Classificação de Solos. $2^{\text {a }}$ Ed. Rio de Janeiro, 2006.

FRYIRS, K. A. et al. Catchment-scale (dis)connectivity in sediment flux in the upper Hunter catchment, New South Wales, Australia. Geomorphology, v. 89, p. 297-316, 2007.

FRYIRS, K. A. (Dis)Connectivity in catchment sediment cascades: a fresh look at sediment delivery problem. Earth Surface Process and Landforms, v. 38, p. 30-46, 2013.

FRYIRS, K. A.; BRIERLEY, G. Naturalness and place River Rehabilitation. Ecology and Society, v. 14, n. 1, p. 20, 2009.

GRAF, W. L. Fluvial Processes in Drylands Rivers. The Blackburn Press: New Jersey, 1988.

KARNIELLE, A.; ASHER, J. B. A daily runoff simulation in semi-arid waterseds based on soil water deficit calculations. Journal of Hidrology, n. 149, p. 9-25, 1993.

SCHUMM, S. A. The Fluvial System. New Jersey: The Blackburn Press, 1977.

SOUZA, J. O. P. Sistema fluvial e açudagem no semi-árido, relação entre a conectividade da paisagem e dinâmica da precipitação, na bacia de drenagem do riacho do saco, Serra Talhada, Pernambuco. (Dissertação de mestrado) - Programa de Pós-Graduação em Geografia: UFPE, Recife, 2011.

SOUZA, J. O. P. Dos sistemas ambientais ao sistema fluvial: uma revisão de conceitos. Caminhos da Geografia, Uberlândia, v. 14, n. $46,224-233,2013$. 
SOUZA, J. O. P.; CORREA, A. C. B. Conectividade e área de captação efetiva de um sistema fluvial semiárido: bacia do riacho Mulungu, Belém de São Francisco-PE. Sociedade e Natureza, Uberlândia, ano 24, n. 2, 319-332, maio/ago. 2012.

VIEIRA, V. P. P. B. Desafios da gestão integrada de recursos hídricos no Semi-árido. Revista Brasileira de Recursos Hídricos, v. 8, n. 2, p. 7-17, abr./jun. 2003. 